\title{
Editorial
}

\section{Matronas y Matrones: Pilar fundamental en la Salud Sexual y Reproductiva Chilena.}

'La historia de la labor médica en el ámbito ginecológico y obstétrico en nuestro país está ligada en forma férrea a Matronas y Matrones, por más de 180 años- desde la fundación de la Escuela de Obstetricia cuyo primer director fue el Dr. Lorenzo Sazié-.

Durante todo este tiempo, su trabajo profesional y abnegado, en profunda colaboración con los ginecoobstetras, ha permitido obtener las actuales condiciones de trabajo, que dan como resultado los excelentes indicadores de Salud Reproductiva y Perinatal, que nos destacan como los mejores de la región y absolutamente a nivel de los países desarrollados.

En el contexto de la discusión actual, en relación con la Norma Administrativa 21, contenida en el Código Sanitario, este Directorio quiere manifestar lo siguiente:

Solidarizamos absolutamente las demandas técnicas esgrimidas por Matronas y Matrones de nuestro país, en relación al fallo de la Contraloría General de la República, sobre la Norma 21, ya que los logros antes mencionados, corresponden a una labor en equipo con roles, funciones y atribuciones, claramente establecidas y vividas en conjunto por más de un siglo y medio. La abnegada labor de este especial estamento, que comienza en los consultorios de atención primaria, pasando por control maternal y ginecológico, programas especiales, llegando a uno de los momentos culmines de su quehacer, parto y puerperio fisiológico, y siendo un pilar fundamental en Alto Riesgo, Ginecología y Neonatología.

Por tanto reconocemos, valoramos y compartimos la definición y descripción de la labor de matronas y matrones que realizó el MINSAL al dictar la Norma 21, detallando así acertadamente los ámbitos de desempeño de la Matronería en nuestro país.

Es por ello que solicitamos a los entes competentes a que realicen las modificaciones necesarias del Código Sanitario para que las Matronas y Matrones sigan desempeñándose tal como lo han realizado hasta la fecha y bajo las definiciones de la citada Norma.

\section{Directorio Sociedad Chilena de Obstetricia y Ginecología}

